\begin{tabular}{|c|c|c|}
\hline$\bigcup_{\text {INESEG }}$ & $\begin{array}{l}\text { INTERNATIONAL } \\
\text { ENGINEERING, } \\
\text { SCIENCE AND } \\
\text { EDUCATION } \\
\text { GROUP (PUBLISHER) }\end{array}$ & 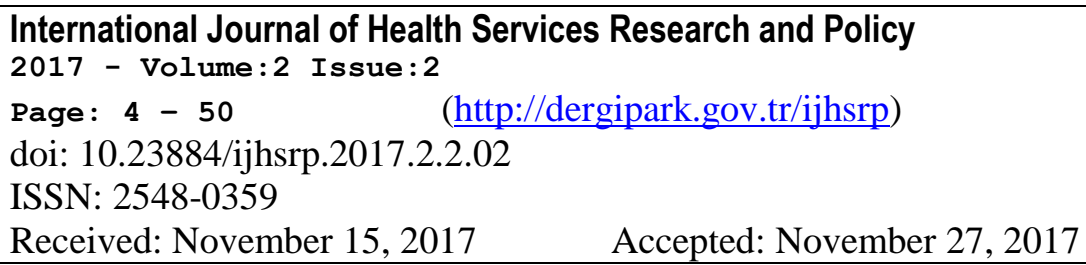 \\
\hline
\end{tabular}

\title{
EXPERIMENTAL INVESTIGATION OF THE EFFECTS OF PROBIOTIC SUPPLEMENTATION ON OBESITY AND INFLAMMATION IN OBESE RATS
}

\author{
Gül Eda Kılınç ${ }^{l}$, Mehtap Ünlü Sögüt ${ }^{l}$
}

Ondokuz Mayls University, Faculty of Health Sciences, Department of Nutrition and Dietetics,

Samsun

*Corresponding author; guleda.kilinc@omu.edu.tr

$T N F-\alpha$ levels of antiinflammatory and proinflammatory markers were used to investigate effects Obesity is a disease that occurs when body has many endocrine and metabolic functions and fat tissue is higher than normal. There is strong relationship between obesity and inflammation due to production of numerous lipid molecules called adipokines, such as leptin, tumor necrosis factor (TNF- $\alpha$ ), interleukins and adiponectin. It was aimed to study obesity and effect on inflammation in experimentally obese animal model study apllied probiotic supplementation. Three different test animal groups were formed. For this purpose; IL-10 and TNF- $\alpha$ on inflammation; leptin levels were used for investigating effect on development of obesity and total cholesterol, HDL and LDL levels from lipid profiles were planned to examine. In obtained serum samples, these parameters were determined by sandwich ELISA technique with commercially available kits. Mean weights at the beginning of study and at the end of 8

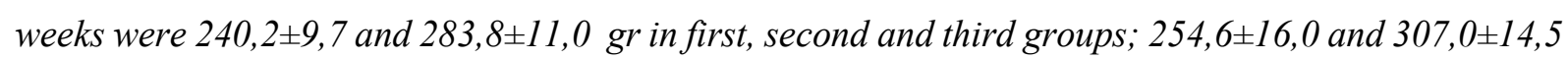

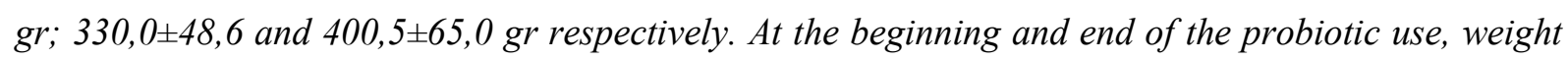

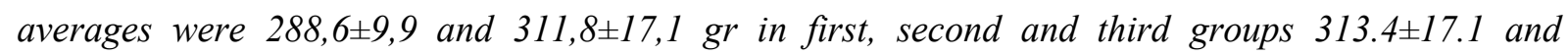
$339.6 \pm 19.7 \mathrm{gr} ; 412,0 \pm 67,7$ and 422,0 $\pm 71,1 \mathrm{gr}$ respectively. When weights were evaluated before and after probiotic use of third group, weight gain was decreased. Although there was no significant difference in HDL, LDL, IL-10 and leptin levels among all group, there was significant difference in total cholesterol and TNF- $\alpha$ values $(p<0,05)$. Compared to first group and second group, there was significant difference in total cholesterol and TNF- $\alpha$ values, in second and third groups there was significant difference in total cholesterol values $(p<0,05)$. As result; probiotics are recognized as living organisms when taken in sufficient quantities, affect health of environment positively, and these beneficial effects are considered to extend to obesity inflammatory diseases. Probiotic supplementation of normal diet may be healthy approach to prevention of various diseases. In order to spread this application to society as whole, it is necessary to increase number of works.

Key words: obesity, inflammation, probiotic 


\section{Introduction}

Obesity is a disease characterized by excessive fat tissue accumulation in the adipose tissue due to increased consumption of high-energy foods and decreased physical activity, which has increased in recent years [1]. Adipose tissue is involved in the synthesis of "adipokines", which are defined as metabolically active proteins [2]. While adipokines such as adiponectin and leptin play a role in obesity, adipokines such as adiponectin, visfatin, resistin and leptin are involved in immun system metabolism [3]. The leptin hormone, one of the adipokines, acts on the hypothalamus to increase energy expenditure and to produce a feeling of satiety [4]. It is also similar to helicase cytokines family, structurally containing IL-2 and growth hormone1 and it is thought to have pro-inflammatory activities by stimulating TNF-a and IL-6 [5].

Probiotics are defined as live microorganisms that provide beneficial effects to the health of the environment when taken in sufficient quantities and play a role in the prevention of obesity and inflammation by various mechanisms [6], [7]. Probiotics are effective on the immune system by inducing mucus production by signaling lactobacilli, activating macrophages, increasing secretory IgA and neutrophils, inhibiting the release of inflammatory cytokines, and increasing peripheral Ig levels [8].

When the relationship between obesity and probiotics is examined, some hypotheses have been suggested that intestinal microbiota is effective on diseases with various mechanisms. The first one is the hypothesis of energy extraction. According to this hypothesis, intestinal microbiota accomplishes production of short chain fatty acids (SCFA) from nondigestible polysaccharides and oligosaccharides that escape proximal digestion and absorption and provides additional energy [9], [10].

Another hypothesis that intestinal microbiota affects obesity is based on the relationship between the gut and the brain. The intestinal-brain axis, which exhibits a bidirectional interaction, with the role of blood glucose level, adipocyte function and energy balance modulates the short-term hunger and satiety mechanism by providing the passage and distribution of nutrients through the gastrointestinal tract. In this way, it can lead to changes in eating behavior that are effective on food intake [11].

Based on this information; we aimed to investigate the effects of probiotic supplements on obesity and inflammation in experimental models of obese animals.

\section{Material and Methods}

The rats to be used in our study were obtained from Ondokuz May1s University Experimental Animal Application and Research Center and the steps related to animal research were carried out in this center. In this study; the first group consisted of the control diet fed with the standard diet, the second group was the obese group fed on the high fat diet, and the third group consisted of the obese group with the probiotic addition to the high fat diet. Groups of animals outside the control group were fed a high fat diet for 8 weeks to form an obese rat model. After the 8th week, the third group was given probiotic supplement for 4 weeks. L. acidophilus, B. lactis, L. paracasei and L. rhamnosus strains were used as probiotic supplement. In addition, rats in each group were weighed weekly and their body weights were measured. For this purpose, IL-10 and TNF- $\alpha$ on inflammation; leptin levels were used 
for investigating effect on development of obesity and total cholesterol, HDL and LDL levels from lipid profiles were planned to examine. In obtained serum samples, these parameters were determined by sandwich ELISA technique with commercially available kits (Relassay, Turkey). Statistical SPSS-20 package program was used for analysis of study data. $p<0.05$ was accepted as statistically significant.

\section{Results}

According to the results of the study, the following findings were obtained. In Table 1, the weighted average of all groups at baseline, after $8^{\text {th }}$ week, at baseline and after probiotic administration was compared.

TABLE 1. COMPARISON OF THE AVERAGE GROUP WEIGHT

\begin{tabular}{|c|c|c|c|c|c|c|c|}
\hline & \multirow[b]{2}{*}{ Group 1} & \multirow[b]{2}{*}{ Group 2} & \multirow[b]{2}{*}{ Group 3} & \multicolumn{4}{|c|}{$p$} \\
\hline & & & & $\begin{array}{c}\text { Group } \\
1-2\end{array}$ & $\begin{array}{c}\text { Group } \\
1-3\end{array}$ & $\begin{array}{c}\text { Group } \\
2-3\end{array}$ & $\begin{array}{c}\text { All } \\
\text { groups }\end{array}$ \\
\hline $\begin{array}{c}\text { Baseline } \\
\text { (gr) }\end{array}$ & $240,2 \pm 9,7$ & $254,6 \pm 16,0$ & $330,0 \pm 48,6$ & 0,345 & 0,094 & 0,137 & $0,001 *$ \\
\hline $\begin{array}{l}\text { Week of } \\
8^{\text {th }}(\text { gr })\end{array}$ & $283,8 \pm 11,0$ & $307,0 \pm 14,5$ & $400,5 \pm 65,0$ & 0,068 & 0,103 & 0,172 & $0,001 *$ \\
\hline $\begin{array}{c}\text { Baseline } \\
\text { of } \\
\text { probiotic } \\
\text { (gr) }\end{array}$ & $288,6 \pm 9,9$ & $313,4 \pm 17,1$ & $412,0 \pm 67,7$ & 0,083 & 0,100 & 0,166 & $0,001 *$ \\
\hline $\begin{array}{c}\text { After } \\
\text { probiotic } \\
\text { (gr) }\end{array}$ & $311,8 \pm 17,1$ & $339,6 \pm 19,7$ & $422,0 \pm 71,1$ & 0,128 & 0,143 & 0,271 & $0,005^{*}$ \\
\hline
\end{tabular}

When examined in Table 1 the mean weights at the beginning of the study and at the end of 8 weeks were $240.2 \pm 9.7$ and $283.8 \pm 11.0$ gr, respectively in the first, second and third groups; $254.6 \pm$ 16.0 and $307.0 \pm 14.5 \mathrm{gr} ; 330,0 \pm 48,6$ and $400,5 \pm 65,0 \mathrm{gr}$, respectively. During the course of probiotic use the mean weights at the beginning and the end were $288,6 \pm 9,9$ and $311,8 \pm 17,1$ gr, respectively in the first, second and third groups; $313.4 \pm 17.1$ and $339.6 \pm 19.7 \mathrm{gr} ; 412,0 \pm 67,7$ and 422,0 $\pm 71,1 \mathrm{gr}$, respectively. Significant differences were found between the groups at baseline, week $8^{\text {th }}$, according to the weights at the beginning and after probiotic $(\mathrm{p}<0,05)$.

In Figure 1, weight averages before and after the use of probiotics were compared and weight gains were evaluated according to groups. 


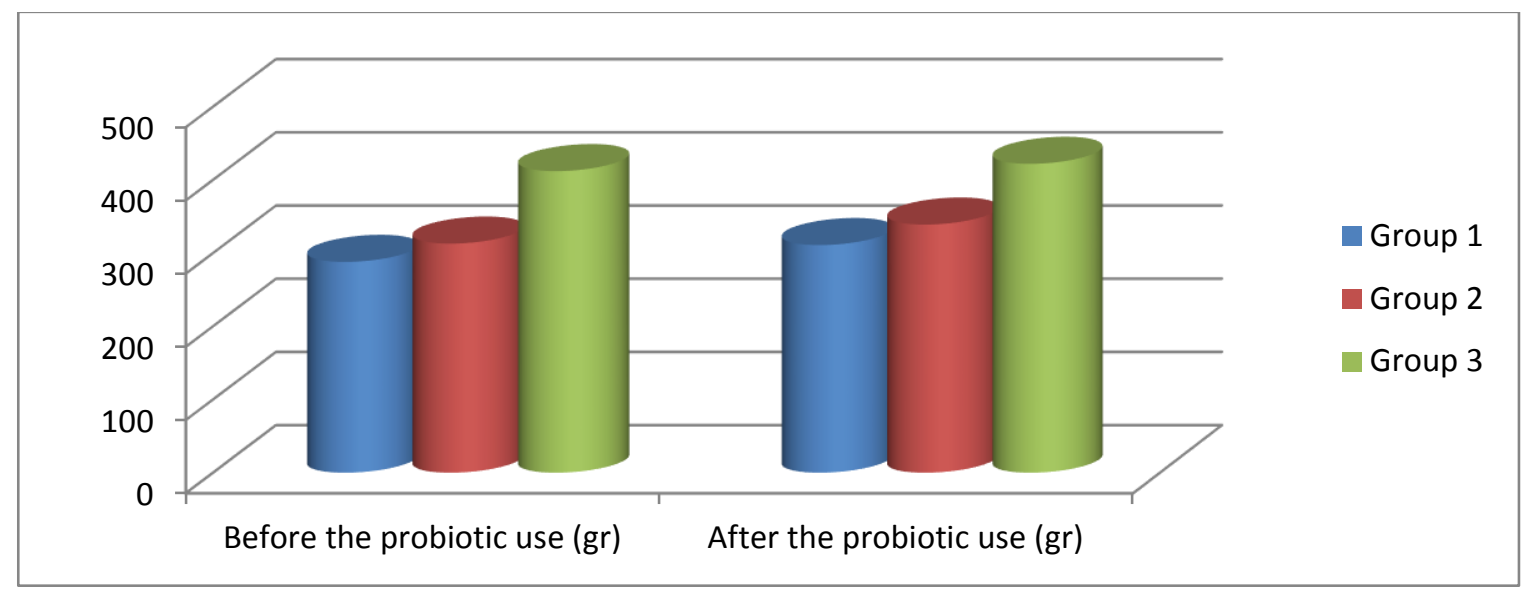

Figure 1. Weight Averages After The Use Of Probiotic

When the effects of probiotic use on weight change were examined, it was determined that group with probiotic use (Group 3) had the least weight gain with 10,0 $\pm 27,2$ gr, group with high fat diet (Group 2) had the highest weight gain with 26,2 \pm 7,1 gr. The mean Body Mass Index (BMI) after 8 weeks in all the study groups were $0.49 \pm 0,01,0,53 \pm 0,02$ and $0,69 \pm 0,11$ in the first, second and third groups respectively, the mean BMI after probiotic use was determined as $0,54 \pm 0,03,0,59 \pm 0,04$ and $0,73 \pm 0,12$ in the first, second and third groups, respectively. When all groups were compared, the change in BMI after probiotic use was statistically significant $(\mathrm{p}<0.05)$.

In Table 2, Among the inflammatory markers; TNF- $\alpha$ and IL-10, HDL, LDL and total cholesterol levels from lipid profiles and leptin levels from obesity markers were examined of all groups.

TABLE 2. COMPARISON OF INFLAMMATORY, LIPID AND OBESITY MARKERS

\begin{tabular}{|c|c|c|c|c|c|c|c|}
\hline & \multirow[b]{2}{*}{ Group 1} & \multirow[b]{2}{*}{ Group 2} & \multirow[b]{2}{*}{ Group 3} & \multicolumn{4}{|c|}{$p$} \\
\hline & & & & $\begin{array}{c}\text { Group } \\
1-2\end{array}$ & $\begin{array}{c}\text { Group } \\
1-3\end{array}$ & $\begin{array}{c}\text { Group } \\
2-3\end{array}$ & $\begin{array}{c}\text { All } \\
\text { Groups }\end{array}$ \\
\hline $\begin{array}{c}\text { HDL } \\
(\mu \mathrm{g} / \mathrm{ml})\end{array}$ & $21,7 \pm 0,7$ & $21 \pm 2,6$ & $18,3 \pm 6,3$ & 0,600 & 0,268 & 0,806 & 0,600 \\
\hline $\begin{array}{c}\text { LDL } \\
(\mu \mathrm{g} / \mathrm{ml})\end{array}$ & $31,5 \pm 4,0$ & $43,1 \pm 11,8$ & $31,9 \pm 2,9$ & 0,058 & 0,805 & 0,059 & 0,083 \\
\hline $\begin{array}{c}\text { Total } \\
\text { kolesterol } \\
(\mathbf{m m o l} / \mathbf{L})\end{array}$ & $13,7 \pm 2,9$ & $22,3 \pm 4,0$ & $14,9 \pm 3,0$ & $0,005 *$ & 0,584 & $0,018 *$ & $0,004 *$ \\
\hline $\begin{array}{c}\text { Leptin } \\
\text { (ng/L) }\end{array}$ & $2069,3 \pm 121,6$ & $2165,3 \pm 80,9$ & $2026,7 \pm 106,7$ & 0,193 & 0,530 & 0,058 & 0,149 \\
\hline $\begin{array}{l}\text { TNF- } \alpha \\
(n g / L)\end{array}$ & $1308,6 \pm 177,1$ & $1758,7 \pm 196$ & $1328,5 \pm 92$ & $0,005 *$ & 0,921 & 0,067 & $0,034 *$ \\
\hline
\end{tabular}




\begin{tabular}{cccccccc}
\hline $\begin{array}{c}\text { IL-10 } \\
(\mathbf{p g} / \mathbf{m l})\end{array}$ & $2086,1 \pm 400,2$ & $1698,4 \pm 50,6$ & $2169,2 \pm 402,4$ & 0,219 & 0,612 & 0,093 & 0,213 \\
\hline
\end{tabular}

$* p<0,05$

When the averages of obesity and inflammatory markers were evaluated according to the study groups, HDL averages in the first, second and third groups were $21.7 \pm 0.7,21 \pm 2.6$ and $18.3 \pm 6.3 \mu \mathrm{g}$ / $\mathrm{ml}$, respectively; LDL averages were $31.5 \pm 4,43.1 \pm 11.8$ and $31.9 \pm 2.9 \mu \mathrm{g} / \mathrm{ml}$; total cholesterol averages $13.7 \pm 2.9,22.3 \pm 4$ and $14.9 \pm 3 \mathrm{mmol} / \mathrm{L}$; leptin averages were determined as $2069.3 \pm 121.6$, $2165.3 \pm 80.9$ and $2026.7 \pm 106.7 \mathrm{ng} / \mathrm{L}$, respectively. In the first, second and third groups, the TNF- $\alpha$ averages were 1308,6 $\pm 177,1,1758,7 \pm 196$ and 1328,5 $\pm 392 \mathrm{ng} / \mathrm{L}$; The mean IL-10 was 2086,1 \pm $400,2,1698,4 \pm 50,6$ and $2169,2 \pm 402,4 \mathrm{pg} / \mathrm{ml}$.

While there was a increase the mean LDL, total cholesterol, leptin and TNF- $\alpha$ levels, there was a decrease in IL-10 level, which a cytokine with anti-inflammatory properties, in the group fed with high fat diet (Group 2) increased compared to the other groups. Although there was no significant difference in HDL, LDL, IL-10 and leptin levels among all groups ( $p>0,05)$, there was a statistically significant difference in total cholesterol and TNF- $\alpha$ values $(p<0,05)$. Compared to the first group and the third group, no significant difference was observed in all values, but when comparing the first group and the second group, there was a significant difference in total cholesterol and TNF- $\alpha$ values $(p<0,05)$. When the second and third groups were compared, a significant difference was found in total cholesterol values $(\mathrm{p}<0,05)$.

\section{Discussion}

Literature studies have shown that Lactobacillus and Bifidobacterium spp. Are antiobesity and antiinflammatory effects in many studies. Yoo et al. found an increase in body weight gain and fat accumulation and an increase in cholesterol and proinflammatory cytokines after probiotic supplementation with Lactobacillus curvatus and Lactobacillus plantarum in obese rats fed with high fat-high cholesterol diet for 9 weeks [12]. In another study conducted during 7 weeks, body weight gain, total cholesterol, HDL, LDL, triglycerides, glucose, and leptin levels were detected a reduction after the addition of probiotic containing $B$. longum to the diet of high fat rats [13]. In another study of probiotic reinforcement containing Bacteroides uniformis strain in experimental animals fed on a high fat diet, a reduction was determined in body weight gain, liver lipid content, serum cholesterol, triglyceride, glucose, insulin and leptin levels [14]. In a study using Lactobacillus curvatus and Lactobacillus plantarum species as probiotic supplement for 2 weeks in mice in which the obese rat model was formed after 8 weeks, a decrease was detected in the proinflammatory genes in the adipose tissue [15].

In our study, similar results were observed to other studies. After probiotic application containing L. acidophilus, B.lactis, L. paracasei and L. rhamnosus strains for 4 weeks, there was a decrease in body weight gain, total cholesterol, LDL, leptin and TNF- $\alpha$ levels, and an increase in IL-10 which a cytokine with antiinflammatory properties. There was no change in HDL levels. 


\section{Conclusion}

As a result; intestinal microbiology and permeability play a role on inflammatory system and obesity by various mechanisms. Probiotic supplement is thought to be a key strategy that can contribute to the prevention of complications related to obesity and obesity by regulating intestinal permeability and by changing intestinal microbiota to provide immune system activation. It is also thought that it will be useful to clarify issues such as effect mechanism, correct microorganism, correct strains by carrying out more comprehensive studies on the subject.

\section{References}

[1] Escobedo, N., Oliver, G., The Lymphatic Vasculature: Its Role in Adipose Metabolism and Obesity, Cell Metabolism, 26 (2017), 4, pp. 598-609.

[2] Gnacinska, M., Malgorzewicz, S., Stojek, M., Lysiak-Szydlowska, W., Sworczak, K., Role of adipokines in complications related to obesity. A review, Advances in medical sciences, 54 (2009), 2, pp. 150-157.

[3] Aktaş, G., Şit, M., Tekçe, H., Yeni adipokinler: Leptin, adiponektin ve omentin, Abant Medical Journal, 2 (2013), 1, pp. 56-62.

[4] Dragano, N. R., Haddad-Tovolli, R., Velloso, L. A., Leptin, Neuroinflammation and Obesity, In Endocrine Immunology, 48 (2017), pp. 84-96.

[5] Ouchi, N., Parker, J. L., Lugus, J. J., Walsh, K., Adipokines in inflammation and metabolic disease, Nature Reviews Immunology, 11 (2011), 2, pp. 85-97.

[6] Zimmermann, P., Curtis, N., The influence of probiotics on vaccine responses-A systematic review, Vaccine, (2017).

[7] Cox, A. J., West, N. P., Cripps, A. W., Obesity, inflammation, and the gut microbiota, The lancet Diabetes \& endocrinology, 3 (2015), 3, pp. 207-215.

[8] Plaza-Diaz, J., Gomez-Llorente, C., Fontana, L., Gil, A., Modulation of immunity and inflammatory gene expression in the gut, in inflammatory diseases of the gut and in the liver by probiotics, . World Journal of Gastroenterology: WJG, 20 (2014), 42, pp. 15632-15649.

[9] Moise, A. M. R., The Gut Microbiome: Exploring the Connection between Microbes, Diet, and Health, ABC-CLIO, 2017.

[10] Delzenne, N. M., Neyrinck, A. M., Bäckhed, F., Cani, P. D., Targeting gut microbiota in obesity: effects of prebiotics and probiotics, Nature Reviews Endocrinology, 7 (2011), 11, pp. 639-646.

[11] Hussain, S. S., Bloom, S. R., The regulation of food intake by the gut-brain axis: implications for obesity, International Journal of Obesity, 37 (2013), 5, pp. 625-633. 
[12] Yoo, S. R., Kim, Y. J., Park, D. Y., Jung, U. J., Jeon, S. M., Ahn, Y. T., Choi, M. S., Probiotics L. plantarum and L. curvatus in Combination Alter Hepatic Lipid Metabolism and Suppress Diet Induced Obesity. Obesity, 21 (2013), 12, pp. 2571-2578.

[13] An, H. M., Park, S. Y., Lee, D. K., Kim, J. R., Cha, M. K., Lee, S. W., Ha, N. J., Antiobesity and lipid-lowering effects of Bifidobacterium spp. in high fat diet-induced obese rats, Lipids in health and disease, 10 (2011), 1, pp. 1-8.

[14] Cano, P. G., Santacruz, A., Moya, Á., Sanz, Y., Bacteroides uniformis CECT 7771 ameliorates metabolic and immunological dysfunction in mice with high-fat-diet induced obesity, PloS one, 7 (2012), 7, e41079.

[15] Park, D. Y., Ahn, Y. T., Park, S. H., Huh, C. S., Yoo, S. R., Yu, R., Choi, M. S., Supplementation of Lactobacillus curvatus HY7601 and Lactobacillus plantarum KY1032 in diet-induced obese mice is associated with gut microbial changes and reduction in obesity, PloS one, 8 (2013), 3, e59470. 